\title{
Research on Innovation of Enterprise Brand Management Based on Network Public Opinion
}

\author{
Zeng Sumei \\ Guangzhou College of Technology and Business, Guangzhou, China, 510850
}

Keywords: Network public opinion; brand management; innovation

\begin{abstract}
In order to establish a correct brand concept, it is necessary to standardize the brand road, so that enterprises have high value brand and stand out in the industry. So this paper finds out the countermeasures of brand enterprise risk management by studying the related concepts of brand shaping and brand maintenance based on network public opinion.
\end{abstract}

In order for enterprises to win in the competition, it is very necessary to give network public opinion brand building. How to shape the brand and how to maintain the brand, how to deal with the risk management of brand enterprises, is a hot topic of brand enterprises.

\section{Brand building based on network public opinion}

\subsection{Brand positioning}

To implement the brand strategy, we should strengthen market research, avoid brand positioning in saturated markets and industries with monopolistic brands as far as possible, subdivide markets, design and develop brand connotations and core values, such as developing green product brands for environmental protection and health, and old brand for population aging. Under the network environment, through the network public opinion, we can more widely and comprehensively understand the changes and characteristics of consumers' needs, do a better job of market research before product development, find new combinations of different characteristics in different market segments, and shape suitable and powerful brands with different advantages. By using search engines, enterprises can contact potential users more widely, understand the values and lifestyles of today's consumers, maintain a high degree of consistency between corporate brands and customers, create harmonious relations, and make brands quickly occupy the market. Enterprises can also publish public opinions through the Internet that are conducive to customers' repeated purchasing behavior, and improve and maintain brand loyalty.

\subsection{Brand marketing}

In brand marketing management, enterprises should strengthen the development and design of brand names, as well as the design of visual carriers such as color, font, packaging style, brochures or banners closely related to the brand, and publicize the brand image through the impact of visual 
symbols. Enterprises should change the single brand strategy of advertising communication, attach importance to the application of low-cost marketing methods such as direct marketing and network marketing in brand communication management, and combine the concepts and methods of relationship marketing and integrated marketing with brand marketing, so as to enhance the brand value of enterprises in an all-round way. Brand marketing based on Internet public opinion can use relationship marketing tools such as club marketing and database marketing to accurately and effectively disseminate enterprise brand information through one-to-one marketing to target customers through internet. This can save a lot of marketing costs, but also faster and more effective than mass media to establish a brand image in the hearts of consumers. Brand marketing based on network public opinion can adopt the following ways. (1) Actively publicize the positive image of the enterprise. (2) Pursuing hot spots and manufacturing concepts. (3) Careful planning.The following table shows:

Table 1. Case study of Edgardo brand marketing

\begin{tabular}{|c|c|}
\hline Time & Case \\
\hline 2008 & Disaster relief donations, network reputation \\
\hline 2009 & Summer Propellant vulgar is "add door" incident \\
\hline $2012-2013$ & The help of Network wins the market in the case of losing Guangzhou medicine \\
\hline
\end{tabular}

\subsection{Brand extension}

Brand extension refers to the use of the reputation of a successful brand with market influence to launch improved products or new products. However, inappropriate brand extension will lead to confusion of product positioning in the minds of consumers, resulting in psychological conflicts among consumers, and may damage the high-quality image of the original well-known brands. Therefore, when carrying out brand extension, enterprises should fully consider the positioning of existing brands, and consider the consistency and "compatibility" of brands. Under the network environment, enterprises can expand the network brand on the basis of traditional brand, make full use of the advantages and resources of the Internet, and get the largest brand network expansion with the lowest cost.Enterprises can build their own brand websites, build a comprehensive network platform, publish objective and neutral public opinion, display the brand in an all-round way, and integrate traditional brand marketing methods such as market research, brand positioning, brand promotion and communication, brand renewal with the Internet, so as to better improve the quality of enterprise brand and enhance it. Brand value. In addition, consumers can be invited to intervene and create brand. In the era of internet, consumers tend to consume independently and actively. Therefore, consumers can be regarded as an organic component of enterprise brand network, so that consumers can actively integrate into the construction of brand.

Through brainstorming on the internet, network public opinion can be guided and the connotation of brand can be enriched. Enterprises can use the network platform to establish a "creative storm" brand community, to communicate and cooperate with consumers continuously and comprehensively, to establish a good interactive relationship, and to create attractive brands with consumers. It can also monitor the public opinion of the online brand community spontaneously formed by consumers, so that active consumers can participate in brand-related activities extensively, so as to establish and maintain a broad and far-reaching brand loyalty relationship. 


\section{Brand Maintenance Based on Network Public Opinion}

Maintenance based on network public opinion is shown in Figure 1, mainly including:

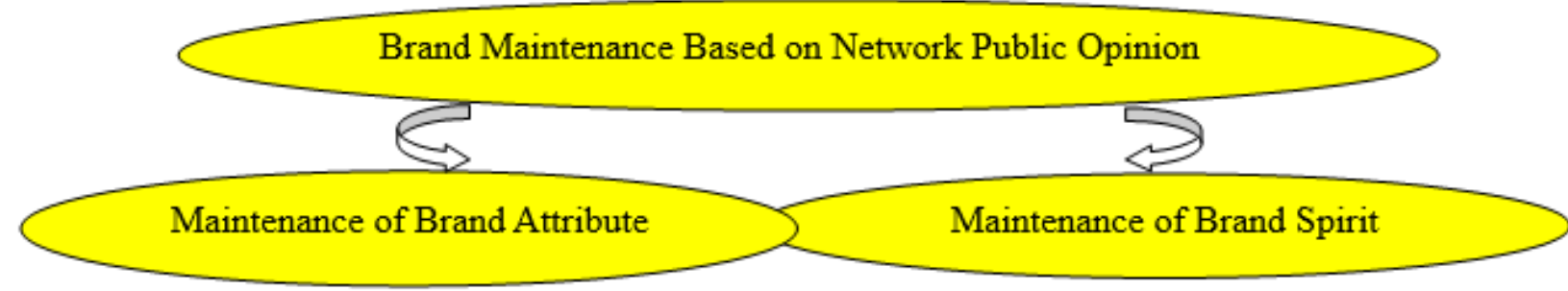

Figure 1. Maintenance of Internet Public Opinion

\subsection{Maintenance of brand attribute}

Enterprise brand management innovation enterprises based on network public opinion should immediately apologize through the media when facing the negative network public opinion of brand quality problems, recall the products with problems, and make corresponding compensation to win the trust of consumers. In addition, the use of third-party authority for brand name correction, negative public opinion generated, it is difficult for enterprises to rely solely on themselves to reverse the negative public sentiment, enterprises should actively invite and cooperate with third-party authority for product inspection and testing, and timely publish the test results, eliminate consumers' negative impression of the brand.

\subsection{Maintenance of brand spirit}

Negative public opinion makes consumers and brand spiritual connotation conflict, weakens the relationship between brand and specific spiritual connotation, and affects brand value. In the face of negative public opinion, enterprises should clarify their responsibilities and respond positively, but can not evade or cover up. Where the problem lies, it is necessary to rectify the production process, deal with the responsible person, recall the product, and compensate for it. Practical actions should be taken to prove that enterprises are brave enough to shoulder the corresponding responsibilities, so as to gain the understanding and trust of consumers, and to enrich the brand spirit.After the brand crisis caused by negative public opinion, enterprises can strengthen their brand image by participating in public welfare activities, such as donating to disaster areas, so as to make their brand have social value such as honesty, social responsibility, and enhance consumers' sense of pride and honor for the brand. In short, enterprises should deal with negative public opinion in a sincere, responsible and positive manner, adopt strong brand maintenance strategies, rebuild the positive image of the brand, and ensure the value-keeping and value-added of brand assets.

3. Establishing long-term mechanism of public opinion management and strengthening brand risk management of enterprises

3.1 To study the characteristics and laws of the development of network public opinion and establish an organizational guarantee mechanism.

\subsubsection{Public opinion monitoring}

For some large enterprises, the daily network public opinion monitoring work can be handed over to the professional public relations company to be responsible for the implementation. Small 
and medium-sized enterprises can appoint a full-time network public opinion monitors to effectively collect and collate the network public opinion information, and then according to the specific situation of enterprises, provide public opinion monitoring and analysis reports and timely feedback to management. At the same time, we should mobilize all staff and workers to participate in the work, take public opinion response as an important index to evaluate the ability to pay attention to and manage public opinion risk, and incorporate it into the evaluation content of department work, and innovate the way of supervision and inspection by establishing and improving the accountability investigation method of public opinion monitoring. According to the characteristics of the enterprise industry, we should strengthen the monitoring of public opinion in the professional field, so as to make the network monitoring without blind spots.

\subsubsection{PUBLIC opinion analysis}

As an enterprise in the information age, it is inevitable to face the public and public opinion, but the openness of network public opinion is very strong. Enterprise network public opinion can be divided into three categories: positive, neutral and negative. Positive information is conducive to the establishment of corporate network image, neutral information can be an important way to understand the enterprise, while negative information is the focus of corporate network public opinion management. According to the content and nature of negative information, negative information can be divided into authentic information, misunderstanding information and fabricated information.Due to the negative information caused by enterprises themselves, enterprises should attach great importance to timely processing. Otherwise, once the negative information is used and amplified, it will not only damage the brand image of the enterprise, but also bring irretrievable losses to the enterprise. This requires enterprises to classify and manage the negative information on the basis of monitoring public opinion. According to the severity of information, they should timely meet and analyze. Different levels should pay attention to adopting different strategies. Focus on the authenticity of public opinion, development trends, attitudes, opinions and emotional fluctuations of network people and other factors, make a correct judgment on the tendency and future development trend of public opinion, so as to make public opinion analysis undoubtedly point, no leakage, no deviation.

\subsubsection{Disposal of public opinion}

According to the analysis of public opinion, enterprises should initiate public opinion response plans and conduct public opinion guidance. The hot public opinion should be tracked by topic, and online comments, replies and comments should be carried out actively. The sensitive information should be monitored and warned effectively. At the same time, different disposal methods are adopted for different negative information. For the true negative information, we should contact the publisher actively at the first time, and solve the relevant problems in time, ensure that everything is implemented, everything has an echo, and control public opinion in the embryonic stage of development.We should make full use of the mainstream media such as radio, radio and government websites to respond positively, sincerely, objectively and openly to false and misinterpreted information. Through timely publication of authoritative information, clarification of facts, positive propaganda and guidance on the problems reflected. At the same time, actively contact website administrators or community moderators, timely delete false negative information, in order to reduce the information audience, reduce adverse effects. After effectively dealing with unexpected network incidents, enterprises also need to earnestly sum up after the event, effectively use public relations means and social resources, and completely eliminate the negative impact. 


\subsection{Master public opinion coping skills to maintain the stability of enterprises}

In the process of brand management, enterprises should strengthen the monitoring of product quality, customer-oriented, and constantly improve their service level. When encountering negative network public opinion, we use public opinion monitoring system to find the source of the crisis, solve problems for customers sincerely, and get customers' active understanding and support. Do a good job of information disclosure.Grasp the pulse of the network group in time, and publish the information they have mastered on their own initiative. When public opinion emerges, we should attach importance to cooperation with the media. In the process of dealing with network public opinion events, we should put an end to such erroneous ways as high-pressure means, distorting facts and masking information, and do a good job of explaining and explaining them pertinently. We should follow the principles of good inducement and persuasion, do a good job in dredging and guiding the public's emotions, let the public speak freely and speak out what they want to say; we should also pay attention to the voice of opinion leaders on the Internet, and guide the public's various understandings to a positive, correct and healthy track, so that enterprises can turn danger into safety and unfavorable opportunities for development.

\section{Summary}

In the process of enterprise development and growth, only by establishing the correct brand concept, taking the standardized brand road and implementing the correct brand management countermeasures, can the enterprise have a high value brand and remain invincible in the fierce competition. Enterprises should make full use of positive public opinion, increase consumers' attention and reputation to brand, and enhance high brand value; reasonably guide the neutral public opinion on the network to enrich the connotation of corporate brand; adopt positive and effective measures to deal with negative public opinion, adhere to the principles of openness, fairness, transparency and authenticity, and search for it most efficiently. To the problem, let the enterprise out of the predicament. In addition, enterprises should also do a good job after the relevant summary, in order to prevent accidents in the future.

\section{Acknowledgement}

Planning for the development of philosophy and Social Sciences in Guangzhou in 2017, 13th Five-Year. Topic name: Research on the cultivation path of local brand characteristics in Guangzhou under the new economic norm, subject number: 2017GZGJ16

\section{References}

[1] Bu Ruination: Reflections on brand building based on network environment [J].2011 (10).

[2] Bhang Jejune and Yang Angular: On the influence of network environment on enterprise brand building

[J].Commerce and Industry, 2011 (24).

[3] Wang Yong, Ministry Xiaoping, Henge Chang long, etc. Network public opinion management is a compulsory course for enterprise development [J].Development Monthly, 2012 (2).

[4] Li Haiphong. Research on the Management Mechanism of Respondent to Network Public Opinion [G], Inhuman University, 2012.

[5] Duo Fijian. How to Improve the Analysis and Response Ability of Internet Public Opinion [J], Inheritance, 2011 (16). 